\title{
Logistic simulation of the bogie bracket welding production line using the RaLC software
}

\author{
Geng Hai-yang, Luo Yi-ping, Ren Hong-juan, Xu Biao \\ College of Automobile Engineering, Shanghai University of Engineering Science, Shanghai, China \\ Email address: \\ ghy198802@sina.com (Geng Haiyang), lyp777@sina.com (Luo Yiping),ren-hongjuan@163.com (Ren Hongjuan), \\ xubiao0813@163.com (Xu Biao)
}

\section{To cite this article:}

Geng Hai-yang, Luo Yi-ping, Ren Hong-juan, Xu Biao. Logistic Simulation of the Bogie Bracket Welding Production Line Using the RaLC Software. Science Research. Vol. 2, No. 3, 2014, pp. 38-42. doi: 10.11648/j.sr.20140203.12

\begin{abstract}
Based on the process design and the production program, the 3D simulation model of the bogie bracket welding production line is built by RaLC. This model was built for the practical problem of the manufacturing logistics design of a bulldozer company joint workshop in Shanghai. The modeling and simulation technique is applied in this process. Then the bogie bracket welding production line is simulated and designed by RaLC. This study puts forward an improvement plan for the bottleneck process in the production line through the analysis of the simulation results, which achieves the optimization design goal of the production line.
\end{abstract}

Keywords: Production Line, Modeling, Simulation, Optimization

\section{Introduction}

Production line simulation is an important part of advanced manufacturing technology(AMT). Its essence is to build an unified model of the various elements and the production process in the production line, and the model reflecting the whole manufacturing process in a virtual environment is simulated by computer. It is more effective to organize the production plants and make more profit[1]. At present, the simulation softwares in the logistics and manufacturing industry include: Flexsim, RaLC, eM-Plant, Witness, Automod, SimuWorks and so on. They have more flexible, intuitive user interfaces and more power. These softwares can be simultaneously displayed $3 \mathrm{D}$ and $2 \mathrm{D}$ animation. They provide a variety of data of production line and the statistical result, and the production bottleneck problem is foud. It can not only help producers to organize production and improve the equipment utilization, but also have a certain guiding significance for the optimization in future.

This article is aiming at the manufacturing logistics optimization problem of a bulldozer company joint workshop in Shanghai. The process of modeling and simulation about the bogie bracket welding production line in the joint bulldozer workshop is studied in detail with the simulation software RaLC. At the moment, this author takes into account the equipment utilization and the distribution of staff, and puts forward the corresponding improvement measures.

\section{RaLC}

RaLC, the logistics simulation software, is developed by Japanese artificial intelligence software company(AIS) independently. RaLC plans and designs the warehousing and distribution center for the simulation of logistics system by the three-dimensional animation software system simulation module. Through the system simulation of the logistics equipment, control systems, operating personnel and business information data, the scientific data verified by simulation is obtained for the logistics and production management and the project planning and design. At the moment, it can provide the fast, practical and visualize three-dimensional animation show, the visual information analysis and discussion, the integration of the staff communication and business exchange, the digital system simulation and the program verification platform for the logistics centers and factories to get all kinds of the best solution.

RaLC software has not only ordinary shelves, forklifts, carts and other commonly used equipment, but also advanced automatic intelligent equipment: automatic stacking machine, AGV(automatic guided vehicle), 
automated rail cars, lifts, automatic warehouse, mobile shelves, rotating shelves and hundreds of kinds of logistics equipment modules corresponding the reality logistics environment. The simulation model completed can achieve the $3 \mathrm{D}$ vivid animation. It is more important to vividly show the operation of the logistics scenario by taking advantage of realistic simulation of logistics data. Meanwhile, RaLC simulation software includes the simulation data analysis tool, which has the ability of the device, time distribution, job content distribution and other data charts through analyzing model log. This reflects the overall operation of logistics, which provides a strong evidence for decision-making improvement.

\section{Process of Modeling}

RaLC logistics simulation software is abstracted and installed on the logistics systems elements of the intelligent robot, transport equipment, cargo, the control system, data, etc. A three-dimensional animation simulation model by computer system is built quickly, which regards 3D animation as a carrier. The process is divided into four parts(Fig1): at first, understanding the capacity of the production line, the principles of the process design as well as supply chain planning, etc. And the process of the whole trailer chassis production line is known. Secondly, the simulation model is built, which includes the establishment of a three-dimensional model, the setting of the relevant parameters and the simulation procedure. Thirdly, the result is output after running the simulation model. At last, the simulation model is analyzed and optimized.

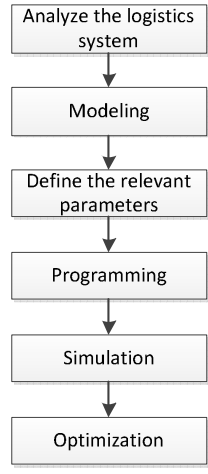

Fig 1. Simulation and optimization flow chart

\section{Modeling}

In the planning and layout of production line, logistics system design is the core, because the type of equipment and the transportation method decides the system layout and affects the architecture of the control system. This article takes a bogie bracket welding production line of a bulldozer company joint workshop in Shanghai as an example. The production line mainly produces the bogie bracket for 320 , $220,410,165$. The main frame of the 320 bogie bracket is shown in Fig 2[2,3].

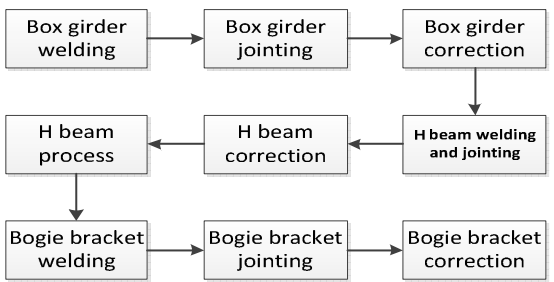

Fig 2. Present bogie bracket welding production line process flow diagram

The design parameters of the production process is shown in Table 1, and the stations of 1-10 and 1-18 are responsible for the parts before a station, which have no parts store.

Table 1. The relevant parameters of production line

\begin{tabular}{|c|c|c|c|c|c|c|c|c|c|}
\hline Station & $1-01$ & $1-05$ & $1-07$ & $1-08$ & $1-09$ & $1-10$ & $1-15$ & $1-17$ & $1-18$ \\
\hline $\begin{array}{l}\text { Process } \\
\text { content }\end{array}$ & $\begin{array}{c}\text { Box girder } \\
\text { welding }\end{array}$ & $\begin{array}{c}\text { Box girder } \\
\text { jointing }\end{array}$ & $\begin{array}{l}\text { Box girder } \\
\text { correction }\end{array}$ & $\begin{array}{c}H \text { beam } \\
\text { welding and } \\
\text { jointing }\end{array}$ & $\begin{array}{c}\text { H beam } \\
\text { correction }\end{array}$ & $\begin{array}{l}\text { H beam } \\
\text { process }\end{array}$ & $\begin{array}{c}\text { Bogie } \\
\text { bracket } \\
\text { welding }\end{array}$ & $\begin{array}{c}\text { Bogie } \\
\text { bracket } \\
\text { jointing }\end{array}$ & $\begin{array}{c}\text { Bogie } \\
\text { bracket } \\
\text { correction }\end{array}$ \\
\hline $\begin{array}{c}\text { Work } \\
\text { hours(min) }\end{array}$ & 320 & 300 & 160 & 400 & 160 & 90 & 180 & 240 & 40 \\
\hline $\begin{array}{c}\text { Number of } \\
\text { staff }\end{array}$ & 4 & 4 & 2 & 4 & 2 & 2 & 4 & 4 & 1 \\
\hline $\begin{array}{l}\text { Number of } \\
\text { equipment }\end{array}$ & 8 & 3 & 2 & 8 & 1 & 1 & 16 & 8 & 1 \\
\hline
\end{tabular}

Note: 1. The production program is 2500 units/year. Working time is 251 days in a year. The production of welding robots are for three shifts. Operating time is 22.5 hours a day. The apparatus load factor is $\mathrm{K}=0.85$. the structure assembly and welding production for the double shift system, and operating time is 15 hours a day.

2. The time is $3750 \mathrm{~h}$ in the base equipment list of the production line. The apparatus load factor is $\mathrm{K}=0.85$. The number of devices $=($ working hours $/ 60) *$ Annual Programme/ $(250 * 15 * 0.85)$.

The 2D and 3D simulation model of the bogie bracket welding production line is shown in Fig 3 and Fig 4. 


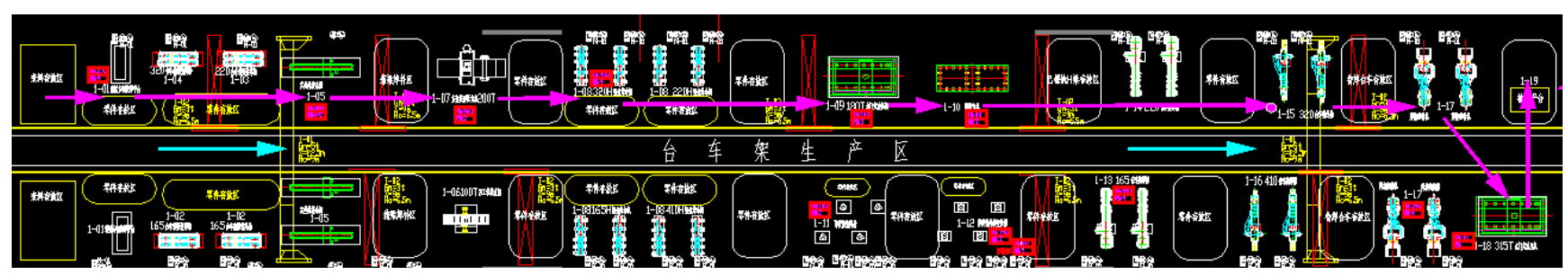

Fig 3. The 2D simulation model of the box girder welding production line

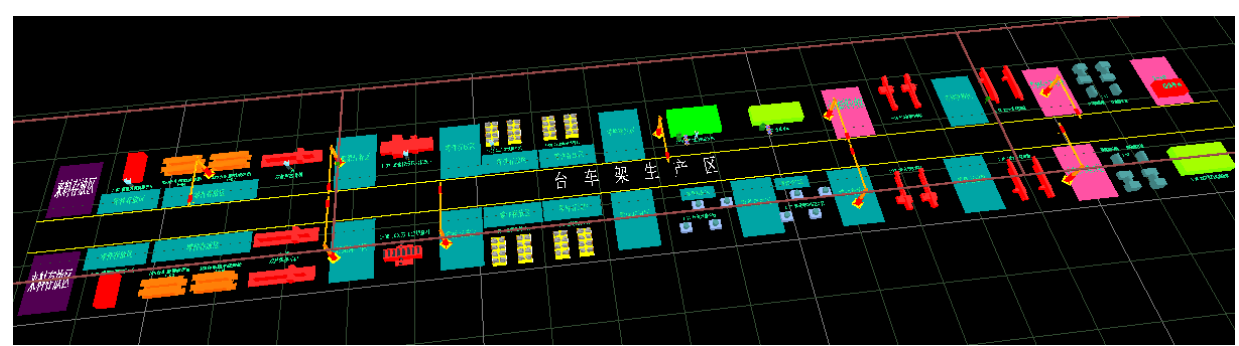

Fig 4. The 3D simulation model of the box girder welding production line

\section{Programming}

Since the logistics between the stations in the entire production line are done mainly by two bridge traveling crane, the programs of them are the main program procedures. Station working time is from the arriving to the leaving. The programs successively detect(one detection per second) whether each station have completed the task. if parts have been completed, the corresponding bridge traveling crane removes the completed parts from the station and hand the processing parts to the station. One of the main program procedures is as follows:

//\%IsBezy:IsBezy=0 the bridge traveling crane is not working; IsBezy=1 the bridge traveling crane is working

IF

EQUAL,\%IsBezy,0//when IsBezy is 0 , it executer the following.

THEN

.......

priority

IF

...... $\quad$ /if parts have been completed at the

station 1-01, the bridge traveling crane removes it.

ELSE_IF

...... - //if there is no parts at the station 1-01, the bridge traveling crane hands the processing parts to the station 1-01.

ELSE_IF

......

priority

ENDIF

ENDIF

//cycle request

REQUEST_NEXT_JOB,@@ThisDeviceName

The return command procedure is as follows:

RETURN_HOME_POS

\section{REPORT_RETURN_HOME_POS, @@ThisDeviceName}

\section{Simulation and Optimization}

The bogie bracket welding production line is composed of a series of discrete events, which includes the handing time of the bogie bracket parts, the moving of forklifts in the manufacturing plant, the break and production schedule of welder, the lifting of the hosting apparatus, etc[4]. Because the bogie bracket parts are large processing units, working hours mainly includes processing time and handling time, so operator standby time $\mathrm{T}_{1}$, the taking delivery of goods time $T_{2}$ and the goods move time $T_{3}$ will refer to the waiting time in this paper. The waiting time $\mathrm{T}_{\mathrm{w}}$ of the station:

$$
T_{w}=\sum_{\mathrm{i}=1}^{N} T_{i}
$$

Equipment utilization is the percentage of actual using time of planned using time of the device. In this paper, the following formula:

$$
\begin{gathered}
\text { equipment utilization }=\text { actual using time } / \text { work hours per } \\
\qquad \operatorname{shift} \times 100 \%
\end{gathered}
$$

The simulation program is imported in the XML operations manager. The model is set the initial value of the simulation time: the simulation length of 7.5 hours (one working day), a fixed time interval as the time pattern: 10 s. Then it will began to be simulated. Through the software LOG analysis tool, the simulation $\log$ is analyzed statistically, which draws the operational status totals table of the major equipment in production line. The data of the equipment utilization is analyzed with excel( Table 2 ). 
Table 2. The equipment utilization of the bogie bracket welding production line before simulation

\begin{tabular}{|c|c|c|c|c|c|c|c|c|c|}
\hline Station & 1-01 & $1-05$ & 1-07 & 1-08 & 1-09 & $1-10$ & $1-15$ & $1-17$ & $1-18$ \\
\hline $\begin{array}{l}\text { Process } \\
\text { content }\end{array}$ & $\begin{array}{l}\text { Box girder } \\
\text { welding }\end{array}$ & $\begin{array}{l}\text { Box girder } \\
\text { jointing }\end{array}$ & $\begin{array}{l}\text { Box girder } \\
\text { correction }\end{array}$ & $\begin{array}{l}\text { H beam } \\
\text { welding and } \\
\text { jointing }\end{array}$ & $\begin{array}{l}\text { H beam } \\
\text { correction }\end{array}$ & $\begin{array}{l}\text { H beam } \\
\text { process }\end{array}$ & $\begin{array}{l}\text { Bogie } \\
\text { bracket } \\
\text { welding }\end{array}$ & $\begin{array}{l}\text { Bogie } \\
\text { bracket } \\
\text { jointing }\end{array}$ & $\begin{array}{l}\text { Bogie } \\
\text { bracket } \\
\text { correction }\end{array}$ \\
\hline $\begin{array}{l}\text { Waiting } \\
\text { time(min) }\end{array}$ & 42.02 & 39.13 & 43.53 & 48.17 & 21.70 & 210 & 73.63 & 56.02 & 200 \\
\hline $\begin{array}{l}\text { Completed } \\
\text { parts }\end{array}$ & 5.2 & 4.1 & 5.1 & 4.0 & 2.7 & 3.0 & 8.3 & 6.2 & 6.9 \\
\hline $\begin{array}{l}\text { Equipment } \\
\text { utilization }\end{array}$ & $90.7 \%$ & $91.3 \%$ & $90.3 \%$ & $89.3 \%$ & $95.2 \%$ & $53.3 \%$ & $83.6 \%$ & $87.6 \%$ & $55.6 \%$ \\
\hline
\end{tabular}

Note: Before the simulation starts, the processing parts at the station 1-09 and 1-18 are assumed to exist.

The above table shows that the maximum utilization of equipment is $315 \mathrm{~T}$ gantry hydraulic machines up 95.5 percent at the station 1-09, where the production logistics bottlenecks is the most likely to occur. In Table 1, there is only one device at the station, which seriously affects the production line progress. At the station 1-10 and 1-18, the equipments are at the low capacity utilization, and the unworking time is relatively long. Therefore, it should consider the restructuring process of the station 1-09 and $1-17$, chang the number of the equipment and the operators or adjust the working time, while the parts store is added. In summary, an increase of $315 \mathrm{~T}$ hydraulic machine and staffs at the station 1-09 or the adjustment of working hours is the most important issue to improve the efficiency of the entire production line.

According to the above simulation results analysis, one operator at the station 1-09 and one parts store at 1-09 and 1-17 are added(namely, the stations of 1-10 and 1-18 has to be processing parts before the simulation). Then the optimized model is simulated by RaLC, and the results as the following (table 3 ).

Table 3. The equipment utilization of the bogie bracket welding production line after simulation

\begin{tabular}{|c|c|c|c|c|c|c|c|c|c|}
\hline Station & $1-01$ & $1-05$ & 1-07 & $1-08$ & 1-09 & $1-10$ & $1-15$ & $1-17$ & $1-18$ \\
\hline $\begin{array}{l}\text { Process } \\
\text { content }\end{array}$ & $\begin{array}{l}\text { Box girder } \\
\text { welding }\end{array}$ & $\begin{array}{l}\text { Box girder } \\
\text { jointing }\end{array}$ & $\begin{array}{l}\text { Box girder } \\
\text { correction }\end{array}$ & $\begin{array}{l}\mathrm{H} \text { beam } \\
\text { welding and } \\
\text { jointing }\end{array}$ & $\begin{array}{l}\text { H beam } \\
\text { correction }\end{array}$ & $\begin{array}{l}\text { H beam } \\
\text { process }\end{array}$ & $\begin{array}{l}\text { Bogie } \\
\text { bracket } \\
\text { welding }\end{array}$ & $\begin{array}{l}\text { Bogie } \\
\text { bracket } \\
\text { jointing }\end{array}$ & $\begin{array}{l}\text { Bogie } \\
\text { bracket } \\
\text { correction }\end{array}$ \\
\hline $\begin{array}{l}\text { Waiting } \\
\text { time(min) }\end{array}$ & 42.02 & 39.13 & 43.53 & 48.17 & 50 & 37.3 & 73.63 & 56.02 & 90 \\
\hline $\begin{array}{l}\text { Completed } \\
\text { parts }\end{array}$ & 5.2 & 4.1 & 5.1 & 4.0 & 5 & 4.6 & 8.3 & 6.2 & 9 \\
\hline $\begin{array}{l}\text { Equipment } \\
\text { utilization }\end{array}$ & $90.7 \%$ & $91.3 \%$ & $90.3 \%$ & $89.3 \%$ & $88.9 \%$ & $91.7 \%$ & $83.6 \%$ & $87.6 \%$ & $80.0 \%$ \\
\hline
\end{tabular}

According to the above table, the equipment utilization of the station 1-09 has been reduced. Simultaneously, the equipment utilization of $1-10$ and $1-18$ exceeds $80 \%$, which meets the requirements of the production line.

\section{Conclusion}

In this paper, RaLC simulation software is used to analyze the production line of bogie bracket for a factory. Analyzing the detailed data records and the intuitive charts generated by simulation, we find the bottleneck process, and improve the layout of equipment, processes and staff rationally. This study provides an important guiding significance for the production layout of scientific planning enterprise and the establishment of a well-functioning logistics system.

\section{Acknowledgements}

This research was supported by the construction of professional platform for modern automobile service engineering in Shanghai city (XKCZ1214).

The first author Geng Haiyang was born in February.1988 in Hebei province. He got bachelor's degree of vehicle engineering in Hubei Polytechnic University in 2012 and now is a Graduate student in Shanghai University of Engineering Science.

The second author Luo Yiping was born in 1966. He gained a master's degree of Industrial Engineering in Shanghai Jiao Tong University in 1987. Now he is a professor in Shanghai University of Engineering Science.

The third author Ren Hongjuan was born in 1978 in Shandong province. She gained a master's degree of Power Machinery and engineering in Shandong University in 2002. Now she is an associate professor in Shanghai University of Engineering Science.

The fourth author Xu Biao was born in September.1990 in Anhui province. He got bachelor's degree of vehicle engineering in Anhui Polytechnic University in 2012 and now is a graduate student in Shanghai University of Engineering Science. 


\section{References}

[1] Zhang Weide, Yan Hongseng, Xu Cheng. Simulation and Application of production line Based on Flexsim[J]. Industrial control computer, 2005, 18(9): 46-47.

[2] Dong $\mathrm{Na}$, Liu Long, Xu Kelin etc. Simulation and Optimization of the facial mask production line Based on Flexsim[J]. Precise Manufacturing \& Automation, 2009, (1): 26-28.

[3] Zheng Shunshui. Study on Techniques Simulation of Production System[J]. Advanced Manufacturing Technology, 2004, 23(4): 22-23.

[4] Li Hua. Modeling and Simulation of Car welding Process Based on eM-Plant[D]. Southwest jiaotong University, 2010. 